\title{
The alleged demise of political human rights at the UN: a reply to Donnelly Philip Alston
}

In a recent article in this journal Jack Donnelly sets out to describe and analyze recent trends in the human rights activities of the United Nations.' Since its publication, his analysis has been cited with approval by a number of commentators including, for example, Louis Sohn, Professor of International Law emeritus at Harvard University, and the conservative thinktank, the Heritage Foundation. ${ }^{2}$ Donnelly argues that, in recent years, the orientation of the UN's human rights program has shifted dramatically to a situation in which issues relating to economic, social, and cultural rights "have become the sum and substance of the UN's human rights program" (p. 635). The result is said to have been "the elimination of civil and political rights from serious international consideration, the absorption of human rights concerns into economic and development issues, and the enshrinement of this particular politicized conception of human rights" (p. 653). His conclusion is that "in the field of human rights, the UN has found its voiceand that voice is not only limited in range, but shrill, and quite disturbing" (p. 655).

The situation would indeed be disturbing if it even vaguely resembled the "bleak" picture painted by Donnelly. The reality, however, is far from the distorted and inaccurate snapshot that he presents. The purpose of this reply is not to present an alternative assessment of recent UN activity in the field of human rights nor is it to debate the substantive merits of General Assembly resolution $32 / 130$, to which a large part of the article in question is devoted.

The views expressed in this reply are those of the author in his personal capacity and not necessarily those of the United Nations.

1. Jack Donnelly, "Recent Trends in UN Human Rights Activity: Description and Polemic," International Organization 35, 4 (1981), pp. 633-55.

2. See Louis Sohn, "The New International Law," American University Law Review 32, 1 (1982), pp. 1-64, n. 337; "The UN and Human Rights: The Double Standard," Heritage Foundation Backgrounder (Washington, D.C., 11 May 1982); and David P. Forsythe, "Socioeconomic Human Rights: The United Nations, the United States, and Beyond," Human Rights Quarterly 4,4 (1982), pp. 433-49.

International Organization 37, 3, Summer $1983 \quad 0020-8183 / 83 / 030537-9 \quad \$ 1.50$

(c) 1983 by the Massachusetts Institute of Technology and the World Peace Foundation 
My limited objectives are to show, first, that Donnelly's sweeping conclusion can in no way be justified on the basis of the scant evidence that he examines and, second, that his conclusion is, in any event, invalid.

The main lines of Donnelly's analysis can, as I understand them, be summarized as follows. The two International Human Rights Convenants, which were adopted by the General Assembly in 1966, appeared to settle the issue of whether either set of rights has priority over the other by putting both on an equal footing. Nevertheless, in practice the United Nations had neglected economic rights. ${ }^{3}$ Beginning with the International Conference on Human Rights, held in Teheran in 1968, an "authoritative reconceptualization of the UN's role and priorities" (p. 634) has taken place. The result is that concern with economic rights issues has "expanded to exclude from consideration virtually everything else" (ibid.). The only evidence proffered in support of this emphatic conclusion is a detailed analysis of General Assembly resolution $32 / 130$ of 1977 , which is said to "codify" the relevant trends.

In essence, the entire argument rests on the validity of taking resolution $32 / 130$ as the embodiment of all UN human rights activity in recent years. In order to justify this extreme narrowness of focus Donnelly first dismisses the relevance for this purpose of organs other than the General Assembly; second, ignores most other General Assembly resolutions on human rights; third, treats the practice of the United Nations as being irrelevant in determining the nature of its activity; and fourth, ignores most other available guides to the real nature of the UN's human rights policies. The acceptability of each of these techniques must be contested.

1. The General Assembly as the only relevant organ. The UN human rights structure is complex. ${ }^{4}$ At its apex is the General Assembly and under it is the Economic and Social Council, two functional commissions (the Commission on Human Rights and the Commission on the Status of Women), one subcommission (the Sub-Commission on Prevention of Discrimination and Protection of Minorities), a wide range of subsidiary bodies established by the Human Rights Commission, and several bodies established pursuant to international treaties (most notably the Human Rights Committee, the Committee on the Elimination of Racial Discrimination, and the Committee on the Elimination of Discrimination against Women). It is the policies and practices of these bodies that shape what Donnelly calls the human rights activity of the United Nations. However, for the purposes of his inquiry he dismisses all bodies other than the General Assembly on the grounds that

3. For the purposes of this reply the term "economic rights" is used to refer to the rights contained in the International Covenant on Economic, Social and Cultural Rights and the term "political rights" to refer to those contained in the International Covenant on Civil and Political Rights.

4. It is described in detail in United Nations Action in the Field of Human Rights (ST/HR/ 2/Rev.1; Sales number E.79.XIV.6), pp. 259-309. 
the Assembly "handles most human rights questions" and is the most appropriate organ for defining "doctrine" (p. 635). In practice, however, the absolute hierarchy that his analysis implies does not exist outside the realm of textbook "organigrams." Thus, for example, with respect to a majority of human rights questions the General Assembly has not initiated relevant UN action; and on some issues its role does not extend very far beyond that of giving its benediction or imprimatur to policies determined by other organs. Moreover, heads of delegation at the Commission on Human Rights tend, by virtue of rank, experience, and prestige, to be more influential than delegates to the Assembly's Third Committee, which deals with human rights issues. This is partly a function of the fact that much essential policy negotiating is done at the Commission, whether before or after the matter has first been raised at the Assembly. In addition, while bodies such as the Human Rights Committee report annually to the General Assembly their policies and practices are not determined by the Assembly. Therefore it is, at best, a gross oversimplification to assess UN human rights activity exclusively on the basis of what is done by the General Assembly.

\section{Resolution 32/130 as the embodiment of all General Assembly human} rights resolutions. Even if, for the sake of argument, it is accepted that the work of the General Assembly alone is a sufficient basis on which to assess the overall human rights activities of the United Nations, the question remains as to whether resolution $32 / 130$ can be taken in total isolation as indicative of the overall program without reference to the Assembly's other actions. It is widely accepted that resolution $32 / 130$ is, for a number of reasons, an important statement of UN doctrine in the field of human rights. However, an assessment of the program of the General Assembly must take account of the totality of that organ's pronouncements. On this basis alone the conclusion that economic rights "have become the sum and substance of the UN's human rights program" (p. 635) is insupportable. Thus in 1977, when resolution 32/130 was adopted, the General Assembly also adopted, on the recommendation of the Third Committee, resolutions dealing inter alia with self-determination, capital punishment, torture and other cruel, inhuman or degrading treatment or punishment, the status of the International Human Rights Covenants, the human rights of migrant workers, the human rights of certain categories of prisoners, the protection of detainees, missing persons in Cyprus, regional human rights arrangements, religious intolerance, and a draft Convention on the Elimination of Discrimination against Women. ${ }^{6}$ These were in addition to other resolutions dealing with what Donnelly refers

5. The reference to the doctrinal competence of the General Assembly does not justify Donnelly's exclusion of other organs, since he is dealing not only with doctrine but with the "sum and substance of the UN's human rights program" (p. 635).

6. See General Assembly resolutions 14, 61, 62, 63, 64, 65, 66, 120, 121, 122, 127, 128, 136,143 , of the $32 \mathrm{~d}$ session. 
to as "the UN's human rights issues": racial discrimination, apartheid, colonialism, human rights in Chile, and the situation in the territories occupied by Israel.' In the years since 1977 the range of issues dealt with by the Assembly has become even broader. For the most part one or two resolutions each year out of an average of perhaps twenty per session have dealt with the issue of economic rights per se. Such evidence clearly contradicts Donnelly's assertion that the consideration of economic rights "has expanded to exclude from consideration virtually everything else" (p. 634).

3. The practice of the United Nations is irrelevant to an overall assessment of its human rights activities. For the period up to 1968 Donnelly acknowledges that UN human rights theory was an unreliable guide to its practice (i.e., while equal weight was given to both sets of rights in theory, in practice economic rights were neglected). Yet for the period after 1968 theory and practice are apparently assumed to be identical, or synonymous, and the analysis of a single resolution is presented as an adequate overall guide. If Donnelly's concern were only with doctrine (or more specifically General Assembly doctrine) his neglect of practice would be understandable. However, his concern, as stated in the title of his article, is with "recent trends in UN human rights activity." Offering an assessment of "the sum and substance of the UN's human rights program" on the basis of an analysis of a single resolution simply will not wash, either academically or politically, or even "polemically."

In order to be persuasive, any such assessment would have to take into account not only the various shortcomings of UN efforts but also the main achievements. Among the latter, reference would have to be made to the successful elaboration of international standards in various fields in recent years; the significant expansion in the scope and depth of the UN's response to situations involving gross violations of human rights (both with respect to specific countries and to more generalized phenomena such as disappeared persons, summary and arbitrary executions, and mass population exoduses); the development of the UN Secretary-General's "good offices" role in human rights matters; the expanded provision of advisory services designed to promote respect for human rights; and a wide range of other initiatives.

4. Other guides to the real nature of the UN's human rights policies. In addition to the fact that Donnelly chooses not to consider a wide range of materials that any serious researcher should consider in making such an

7. Donnelly, p. 636. It may be doubted whether this assessment can be reconciled with earlier statements that the United Nations considers economic rights issues to the virtual exclusion of all else (p. 634). 
assessment, he makes selective use of the materials to which he does refer. ${ }^{8}$ Two examples must suffice in the present reply. He refers to the report of the Secretary-General on the international dimensions of the right to development as "perhaps the most important single [sic] document on the issue" (p. 646, n. 29). ${ }^{9}$ However, he makes no reference whatsoever to the content of this singularly "important" report, thereby ignoring its repeated emphasis on the equal importance of the two sets of rights-an emphasis that runs contrary to his thesis about the policies of the United Nations. ${ }^{10}$ Elsewhere he cites examples purporting to demonstrate "the diffusion of the principles of $32 / 130$ beyond the general topic of alternative approaches and ways and means" (p. 642, n. 23). In fact, all of the examples he gives refer only to one other item - that on economic rights, where the principles in resolution $32 / 130$ are inevitably going to be discussed. Moreover, he neglects to mention that the approach taken to the interpretation of the relevant principles was by no means dominated by a single "majority" view, as is clear from a reading of the Commission's report."

\section{Interpreting resolution $32 / 130$}

In interpreting ar instrument such as a resolution of the General Assembly the greatest importance is to be attached to the actual wording of the instrument. In seeking to understand the full significance of a particular wording resort may usefully be had to the travaux préparatoires, which may provide some indication as to the intentions of the sponsors of the resolution. The travaux préparatoires cannot, however, be taken out of context to support an explanation or interpretation that runs contrary to the clearly expressed provisions of the resolution. In other words, what really counts is the final product rather than the bluff and bluster of the debate.

In his analysis of resolution 32/130 Donnelly prefers to focus on the rhetoric and form of the debates rather than on the substance of the resolution. Thus he concedes at one point that the interdependence of the two sets of rights

8. For example, the resolutions of organs such as the Commission and Sub-Commission, and the various studies and reports presented to different organs either by the Secretary-General or by Special Rapporteurs. Similarly, the number of meetings devoted to the debate on different items provides at least some indication of the priority concerns of a given organ. In 1982 the Commission on Human Rights devoted 5 of its 62 meetings to the item dealing with economic rights, the NIEO, and the right to development.

9. E/CN.4/1334 (1979).

10. Ibid., paras. $117-19,311$, and 314 .

11. This is clearly reflected in the report adopted by the Commission at its 1979 session. "Several speakers emphasized the need to avoid the creation of a hierarchy of rights, and pointed out that resolution $32 / 130$ constituted a delicately balanced package, so that economic, social and cultural rights must be pursued with a constant awareness of the need to respect civil and political rights and of the interrelationship of those rights. Several speakers asserted that economic and social rights were the basis for enjoyment of other rights ..." (E/1979/36, para. 123). 
is enshrined in the text of resolution $32 / 130$ (p. 646). However, he immediately discounts this "facade" on the grounds that "there seem to be two interpretations, one straightforward, beyond question, and the interpretation of but a small minority, the other both contentious and the predominant view" (p. 648). Donnelly manages to dismiss out of hand the "straightforward" interpretation by using the old debating technique of selecting a cluster of statements in debate, all taken from one particular point on the spectrum (he relies mainly on statements by the USSR, Cuba, Hungary, Czechoslovakia, Viet Nam, Iran, Pakistan, and Saudi Arabia), and then depicting that position as being representative of the ideology of the United Nations as a whole. But this technique is neither conducive to rational debate nor scientifically valid. Selective quotations from the travaux préparatoires (no matter how damning) cannot be used to support an interpretation that runs exactly contrary to the wording of the final resolution. The unacceptability of this technique is well illustrated in the following passage: "The provision in [the resolution] misleadingly refers to "violations of human rights of peoples and persons.' The original version of the resolution (A/C.3/32/L.17), however, leaves out 'and persons,' more clearly indicating its priorities" (p. 651). Thus the wording of the resolution is discounted and an interpretation that was specifically rejected during the drafting process is advanced as the "real" one.

In this regard Donnelly must, or at least should, be aware that UN resolutions such as $32 / 130$ invariably contain a number of tediously negotiated, delicately balanced provisions that, by design, not accident as he implies, are capable of being interpreted in different ways to suit different users. But the author ignores this fundamental reality of multilateral negotiations and narrowly interprets each ambiguous provision in the manner most favorable to his overall thesis. The picture presented as a result is one of a virtual conspiracy, which implies that the overwhelming majority of UN member states are, for unspecified reasons, indulging in a continuing exercise in deceit and hypocrisy by adopting texts that in no way reflect their "real" views. The dynamics of the overall process are both more complex and more fluid than this. The importance of maintaining at least a minimal degree of support across the ideological spectrum, which is essential if a resolution such as 32/ 130 is to enjoy continuing influence, serves to ensure that no one ideological group can usefully expropriate the resolution entirely for its own purposes. Any such drastic doctrinal expropriation would clearly be self-defeating.

In reality, of course, there is no denying that some delegates to the General Assembly would like to interpret the formulations in resolution $32 / 130$ in such a way as to give priority to economic rights at the expense of political rights. There are, however, no grounds for proceeding to attribute a badfaith motivation to all, or even the great majority, of the 123 states that supported the resolution in the Assembly. Moreover, Donnelly nowhere explains the fact that not one single state voted against the resolution despite 
the fact that, in his view, it "renounces many of the basic principles of the Universal Declaration and the Covenants" (p. 653).

\section{Other distortions}

Among other points on which issue must also be taken, the following stand out. First, the statement that "only civil and political rights are exempted from serious international scrutiny and truly international norms" (p. 650) is hopelessly at odds with the reality. On the one hand, the United Nations has Special Rapporteurs, Special Representatives, and ad hoc groups examining alleged violations of human rights (essentially focusing on civil and political rights) in countries as diverse as Chile, Poland, El Salvador, Bolivia, and Equatorial Guinea, and phenomena such as missing persons, states of emergency, summary or arbitrary executions, and mass exoduses. In addition the raison d'être of the Human Rights Committee and of the Committee on the Elimination of Racial Discrimination is to give international scrutiny to the civil and political rights performance of states parties to the respective instruments. On the other hand, by contrast, the economic, social, and cultural rights performance of states is currently subject to only very superficial scrutiny, and specific standards on the basis of which such performance could be examined are few and far between (except those of the ILO).

Second, resolution $32 / 130$ states that "the realization of the new international economic order is an essential element for the effective promotion of human rights. ..." On this basis, Donnelly identifies the New International Economic Order (NIEO) as a "right" (p. 650) although no UN human rights organ has ever done so. He then adds that, "in human rights terms it [the NIEO] amounts to but another way of granting priority to economic and social rights in developing countries and further obliterates the uniqueness of human rights issues by incorporating them into ongoing economic concerns" (p. 650, n. 35). This would seem to contradict his earlier recognition that there is an undeniable dependence of human rights on economic development (p. 643). It also seeks to create a highly questionable distinction between "human rights issues" and "ongoing economic concerns." (Is realization of the right to work unrelated to economic issues, or are human rights interpreted as embracing only civil and political rights?)

Third, Donnelly argues that "the right to habeas corpus, freedom from arbitrary arrest and detention, access to courts, and the presumption of innocence" as well as numerous other rights "bear little or no relation to the development process" (p. 645). ${ }^{12}$ In addition to being inconsistent with his earlier statement (p. 643), this demonstrates a remarkable lack of sympathy for the plight of countries such as Uganda where national bankruptcy clearly

12. Emphasis added. 
imposes some limits on the ability of the government to ensure respect for such rights. While political rights violations can never be justified (although they may be partly explained) on economic grounds, it is surely excessive to argue that the realization of political rights bears no relation to the development process.

Fourth, Donnelly laments that "it is not clear that even such a relatively technical area as the UN's advisory services program can be saved from politicization along the lines of resolution $32 / 130$ " (pp. 654-55). The only evidence offered in support of this contention is the example of a seminar on "the effects of the existing unjust international economic order" on human rights, which was held in the framework of the advisory services program. Leaving aside the question of whether the use of the term "unjust" to describe the existing international economic order constitutes undue "politicization," Donnelly should have been aware that such human rights seminars do not in any sense amount to an exercise in technical assistance, although for the sake of convenience the two activities are lumped together under the same administrative umbrella. More serious, however, is his failure even to mention, let alone to examine, any of the relevant initiatives in the field of advisory services in recent years. The most notable of these, involving the provision of technical assistance to Equatorial Guinea after the fall of Macias Nguema, is a clear case in which equal emphasis was placed on the importance of restoring political rights at the same time as improving the enjoyment of economic rights. ${ }^{13}$

In addition to the points raised above, the article is replete with a number of unsubstantiated rhetorical attacks on the United Nations. Such subjective assessments may or may not be valid but it is disappointing that in a journal of the scholarly standing of International Organization he proffers, without any supporting analysis, statements such as these: "Experience has shown that the UN has had little or no effect on the actual implementation of human rights ..." (p. 648, n. 32); and "The UN campaign against racism even today shows little in the way of achievements" (p. 636). Such sweeping assertions may constitute ideal topics for classroom debate or even for detailed academic or political scrutiny but they are hardly appropriate throw away lines in a scholarly analysis, even when the title offers an apology in advance by using the term "polemic." 14

13. See UN docs E/CN.4/1371 (1980); E/CN.4/1439 and Add.1 (1980); E/CN.4/1495(1981); and E/CN.4/1983/17.

14. In this regard reference may be made to a variety of substantially more favorable recent assessments of the UN's human rights endeavors. The International Commission of Jurists considered the Commission on Human Rights" 1982 session to be "remarkable for the number of positive decisions reached on controversial topics" (ICJ Review no. 28 [June 1982], p. 33). One academic observer has concluded that "after thirty years, the Commission has become the world's first intergovernmental body that regularly challenges sovereign nations to explain abusive treatment of their own citizens" (Howard Tolley, "Decision-Making at the United Nations Commission on Human Rights, 1979-82," Human Rights Quarterly 5 [1983], p. 56). And the United States representative to the Commission, in expressing satisfaction with the results of its 1983 session, referred to its "positive work in adopting procedures for keeping cases of human rights violations under constant scrutiny ..." (Richard Schifter, in U.S. Mission to the UN at Geneva, Daily Bulletin, 11 March 1983, p. 5). 


\section{Conclusion}

No issue in the field of international human rights is as complex, as potentially divisive, or as fraught with ideological nuances as that concerning the relationship between the two sets of rights. Donnelly's article is useful insofar as it serves to focus attention on that fact. In practice, the issue is incapable of being permanently "resolved" and the leaning of the debates that surround it will inevitably tend, over time, to seesaw from one side of the ideological spectrum to the other. Within the United Nations, the debate has never been closed, even temporarily as Donnelly claims (pp. 638-39). In theory, the equality of the two sets of rights was recognized immediately by the United Nations in the Universal Declaration of Human Rights of 1948, reaffirmed by the General Assembly in 1950 and 1951 in the process of drafting the Covenants, and given the official imprimatur by the adoption of the two Covenants in 1966. In practice (as well as in the context of the debates to which Donnelly attaches such importance) the argument has always raged and it will continue to do so.

This does not mean that there are no problems. It is clear that the present practice of many states is to neglect or downplay the importance of political rights in favor of economic development (which is all too often not synonymous with the satisfaction of economic rights). Similarly, there is no shortage of academic commentators who would seek to defend such policies. Other commentators have urged that priority be given to particular rights and have implied that their realization can be promoted with minimal, if any, regard for other human rights. ${ }^{15}$

The debate within the major UN human rights organs has also been controversial at times, with both extremes (rather than only one extreme along with the moderate center, as Donnelly implies) ${ }^{16}$ being represented. However, to claim that the result has been "the elimination of civil and political rights from serious international consideration, the absorption of human rights concerns into economic development issues, and the enshrinement of this particular politicized conception of human rights" (p. 653) is simply a travesty of the facts. Rather, the United Nations has devoted considerable attention to the fundamental need to maintain a balance between the two sets of rights. Thus, for example, a recent Secretariat report devotes considerable space to "a critique of some of the grounds adduced for abridging human rights in order to promote economic development."17 In the same vein the General

15. See, for example, Ernst B. Haas, Global Evangelism Rides Again: How to Protect Human Rights without Really Trying (Berkeley: University of California Institute of International Studies, 1978), pp. 45-46.

16. "[B]y the mid seventies it was becoming clear that the western position, which in large measure was reflected in the Covenants, was not merely on the defensive, but had been effectively routed in the UN" (p. 639).

17. E/CN.4/1488, para. 128. 
Assembly adopted a resolution in December 1982, the last preambular and first operative paragraphs of which read as follows:

The General Assembly...

Recalling its resolutions under this item, in particular resolution 32/ 130 of 16 December 1977,

1. Affirms that a primary aim of international co-operation in the field of human rights is a life of freedom and dignity for each human being, that all human rights and fundamental freedoms are indivisible and interrelated and that the promotion and protection of one category of rights should never exempt or excuse States from the promotion and protection of the other. ... ${ }^{18}$

Such statements of principle cannot be dismissed as mere window dressing. Nor can the fact that the large majority of UN human rights resolutions deal primarily with political rather than economic rights issues be reasonably disputed. In sharp contrast to Donnelly's claim that civil and political rights have been eliminated from serious international consideration by the United Nations, the reality is that the principle of the equality of the two sets of rights is alive and well in UN doctrine while the tension that exists in practice between the two sets of rights continues, unavoidably and sometimes appropriately, to characterize its debates.

18. General Assembly resolution $37 / 200$ (adopted by a recorded vote of 81 in favor, 38 against, and 20 abstentions). 